\title{
Vincetoxicum tmoleum Boiss. Taksonunun Genişletilmiş Morfolojik Özellikleri ve Türkiye'deki Yayılışı
}

\author{
Seher GÜVEN ${ }^{1 *}$, Serdar MAKBUL ${ }^{1}$, Kamil COŞKUNÇELEBİ ${ }^{2}$ \\ ${ }^{1}$ Recep Tayyip Erdoğan Üniversitesi, Fen-Edebiyat Fakültesi, Biyoloji Bölümü, Rize, Türkiye \\ ${ }^{2}$ Karadeniz Teknik Üniversitesi, Fen Fakültesi, Biyoloji Bölümü, Trabzon, Türkiye \\ *Sorumlu Yazar/Corresponding Author \\ E-mail: seher.cakmak@erdogan.edu.tr \\ Orcid ID: 0000-0001-8883-8489 \\ Araştırma Makalesi/Research Article \\ Geliş Tarihi/Received: 30.05 .2021 \\ Kabul Tarihi/Accepted:13.10.2021
}

\section{ÖZET}

Bu çalışma ile Türkiye'de geniş bir yayılışa sahip Vincetoxicum tmoleum Boiss. taksonunun fotoğraf ve çizimler ile desteklenmiş morfolojik özellikleri yeniden incelenerek güncel veriler 1şığında ülkemizdeki dağglımı ve tehdit değerlendirmeleri araştırılmıştır. Morfolojik çalışmalar, türün doğal yayılış gösterdiği alanlardan toplanmış ve Recep Tayyip Erdoğan Üniversitesi Biyoloji Bölümü Herbaryumunda (RUB) saklanan örnekler ile ulusal/uluslararası herbaryumlarda bulunan örnekler üzerinden gerçekleştrilmiştir. V. tmoleum dik ve kısa kıvrık tüylü (crisped) gövdesi, belirgin pedunkulu (10-45 mm), yeşilimsi-sarı renkli korollası, yoğun uzun kıvrık yünsü tüylü (lanate) petalleri, parçalı koronası, üçgenimsi korona segmentleri, lanseolat ve kısa kıvrık tüylü (crisped) meyvesi ile karakterize edilmektedir. Bu çalışma ile taksonun Türkiye'de yayılış gösterdiği ve doğrulanmış lokalite sayısı 89 olarak belirlenmiştir. Ayrıca, V. tmoleum taksonunun geniş yayılışlı olduğu, popülasyonlarının güçlü olduğu ve yakın gelecekte bir risk etmenin olmadığı değerlendirilmiştir.

Anahtar Kelimeler: Morfoloji, Türkiye, Vincetoxicum tmoleum, Zilasur

\section{Extended Morphological Characteristics of Vincetoxicum tmoleum Boiss. and Its Distribution in Turkey}

\begin{abstract}
With this study, the morphological features supported by photographs and drawings of Vincetoxicum tmoleum Boiss, which has a wide distribution in Turkey, were re-examined, and its distribution and threat assessments in our country were investigated in the light of current data. Morphological investigations were carried out on the samples collected from natural distribution areas of the species, kept in the Herbarium of the Biology Department at Recep Tayyip Erdoğan University (RUB) and found in national / international herbaria. $V$. tmoleum is characterised with its erect and crisped stem, distinct peduncle (10-45 mm), greenish-yellow corolla, densely lanate petals, deeply parted corona, triangular corona segments, lanceolate and crisped fruit. With this study, the number of confirmed localities of the taxon for Turkey was determined as 89. In addition, it has been evaluated that $V$. tmoleum is a widely distributed taxon, its populations are strong and there is no risk factor in the near future.
\end{abstract}

Keywords: Morphology, Turkey, Vincetoxicum tmoleum, Zilasur

\section{Atıf için (Cite);}

Güven, S., Makbul, S., Çoşkunçelebi, K. (2021). Vincetoxicum tmoleum Boiss. Taksonunun Genişletilmiş Morfolojik Özellikleri ve Türkiye'deki Yayılışı, Recep Tayyip Erdogan University Journal of Science and Engineering, 2(2), 1-12. Doi: 10.53501/rteufemud.945076 


\section{Giriş}

Asclepiadoideae alt familyasının önemli cinsleri arasında yer alan Vincetoxicum Wolf Avustralya ve Uzak Doğu'dan Afrika'ya, Anadolu ve Kafkasya üzerinden güney Rusya, Avrupa ve Kuzey Amerika'ya kadar uzanan geniş bir coğrafik alanda doğal olarak yayılış gösteren 140'1n üzerinde tür ile temsil edilmektedir (Sheeley ve Raynal, 1996; Douglass vd., 2009; Liede-Schumann vd., 2016). Her ne kadar dünyada geniş bir yayılışa sahip olsa da cinsin gen merkezinin Çin (57 tür) ve Japonya (18 tür) olduğu düşünülmektedir (Liede, 1996).

Türkiye Vincetoxicum taksonları üzerinde ilk kapsamlı morfolojik çalışma cinsi revize eden Browicz (1978) tarafından gerçekleştirilmiş ve biri şüpheli kayıt (Vincetoxicum raddeanum Albov) olmak üzere 9 türe ait toplam 11 takson tespit edilmiştir. Türkiye Bitkileri Listesi'nde Vincetoxicum cinsinin, ikisi Türkiye endemiği (V. fuscatum Reichenbach subsp. boissieri (Kusnezov) Browicz ve $V$. parviflorum Decaisne) olmak üzere toplam 10 taksonla (beş tür ve beş alt tür) temsil edildiği ve $V$. raddeanum türünün durumunun teyide muhtaç olduğu rapor edilmiştir (Güner, 2012). Türkiye ve Doğu Ege Adaları Florası'nda ifade edildiği üzere, Vincetoxicum morfolojik olarak birbirine benzer taksonları içerdiğinden, sistematik yönden problemli bir cinstir (Browicz, 1978). Vincetoxicum cinsinde yaygın olarak görülen genetik ve morfolojik varyasyonlar taksonların ayırımında yalnızca geleneksel karakterlere (fenetik) dayalı teşhislerde zorluklara ve hatta yetersizliklere yol açmaktadır. Ülkemiz Vincetoxicum taksonları üzerinde en son değerlendirmeler Güven (2017) tarafindan yapılmıştır. Güven (2017) ve Güven vd. (2015, 2019) ülkemiz taksonlarının ayrımında morfolojik karakterlere ek olarak anatomik, palinolojik, sitolojik ve moleküler verilerin önemli taksonomik katkılar sağladığını ortaya koymuştur. Vincetoxicum taksonlarının ayrımında çiçek morfolojisinin oldukça önemli katkılar sağladığı bilinmektedir (Güven vd., 2015). Benzer şekilde sitolojik ve moleküler verilerin taksonomik problemlerin çözümüne kısmen katkı sağladıkları tespit edilmiştir (Güven vd., 2019).

Ülkemizde geniş yayılış gösteren $V$. tmoleum populasyonları nemli ve kuru habitatlar gibi birbirinden farklı ekolojik ortamlarda yetişme kabiliyetine sahiptir (Browicz, 1978). Türkiye ve Doğu Ege Adaları Florası (Browicz, 1978) kayıtlarında ülkemizin doğusundan batısına kadar çok geniş bir coğrafyada yayılışa sahip olduğu belirtilmektedir. $V$. tmoleum bireyleri yeşilimsi-sarı çiçekleri, dik gövde yapısı ve öbek oluşturan görünümleri ile karakterize edilmektedir. Ülkemiz florası ile ilgili çalışmalarda bu türün bazı taksonomik sorunlarının olduğu ve ülkemiz için şüpheli kayıt olarak verilen $V$. raddeanum türü ile morfolojik benzerlikler gösterdiği belirtilmiştir. Bu nedenle Browicz (1978), $V$. raddeanum türünün $V$. tmoleum'un bir varyetesi veya $V$. tmoleum ile Vincetoxicum canescens (Willd.) Decne türlerinin bir melezi olabileceğini ve bu durumun araştırılması gerektiğini vurgulamıştır. Ancak daha sonra yapılan taksonomik çalışmalar $V$. raddeanum türünün $V$. tmoleum türünün sinonimi (eşad1) olduğunu ortaya koymuştur (Greuter vd., 1984).

Vincetoxicum türleri ülkemizin değişik yörelerinde zehirotu, panzehirotu, kırlangıçkuyruğu, dağbiberi, gâvurbiberi, gâvurüzerliği, hıyaluk, siyek ve zilasur gibi farklı adlarla tanınmaktadır (Baytop, 1984; Tuzlacı, 2011; Doğan, 2008; Altundağ ve Öztürk, 2011; Güner, 2012). Etnobotanik yönden önemli bir bitki gurubunu oluşturan cins üyeleri balgam söktürücü (ekspektoran), idrar söktürücü (diüretik), kusturucu (emetik), terletici (diyaforetik), bağırsak yumuşatıcı (laksatif) ve anti tümör ajan olarak halk tıbbında kullanılmaktadır (Lavault vd., 1999; Nowak ve Kisiel, 2000; DiTommaso vd., 2005). Özellikle $V$. tmoleum taksonunun Doğu Anadolu bölgesinde uyuz ve mantar enfeksiyonlarının iyileştirilmesinde halk ilacı olarak kullanıldığ rapor edilmiştir (Altundağ ve Öztürk 2011). 
$\mathrm{Bu}$ çalışma ile ülkemizde geniş yayılış alanına sahip V. tmolem türünün çizimlerle desteklenmiş ayrıntılı morfolojik özelliklerinin belirlenmesi, güncel veriler 1şıı̆ında ülkemizdeki yayılış alanlarının ortaya konulması ve tehdit sınıfı değerlendirilmesinin yapılarak türün taksonomik durumuna katkılar sağlanması amaçlanmıştır.

\section{Materyal ve Metod}

\subsection{Bitki Materyalleri}

Çalışmanın konusu olan Vincetoxicum tmoleum türüne ait örnekler 2011-2017 y1lları arasında ülkemizde yayılış gösterdiği doğal alanlardan toplanmıştır. Toplanan bitki örnekleri herbaryum örneği haline getirilerek Recep Tayyip Erdoğan Üniversitesi Biyoloji Bölümü Herbaryumu (RUB)'nda saklanmaktadır.

Ülkemizdeki herbaryumlardan ANK, EGE, GAZI, HUB, ISTE, ISTF, ISTO ve KATO ile yurtdışındaki herbaryumlardan B (BerlinAlmanya), LE (St. Petersburg- Rusya) ve TBI (Tiflis-Gürcistan) herbaryumları ziyaret edilerek Vincetoxicum cinsine ait ülkemizden toplanan bitki örnekleri incelenmiştir. Ayrıca E, GOET, JE, K, $\mathrm{P}$ ve $\mathrm{W}$ herbaryumlarında bulunan $V$. tmoleum'a ait bitki örnekleri de sanal ortamda değerlendirilmiştir. İncelenen örneklere ait yayılış bilgileri Ek 1'de verilmiştir.

\subsection{Morfolojik Çalışmalar}

$V$. tmoleum'un morfolojik betiminde öncelikle, başta Türkiye ve Doğu Ege Adaları Florası (Browicz, 1978) olmak üzere, Rus Floras1 (Pobedimova, 1952), Kafkas Florası (Grossheim, 1967), Avrupa Florası (Markgraf, 1972), İran Floras1 (Rechinger, 1970) ve Flora Orientalis (Boissier, 1875)'den yararlanılarak bitkilerin teşhisinde rol oynayan önemli morfolojik karakterler tespit edilmiştir. $\mathrm{Bu}$ karakterler kullanılarak toplanan bitki örnekleri ayrıntılı bir şekilde incelenmiş ve teşhisleri yapılmıştır. Bitki teşhisinde kullanılan morfolojik karakterler "Leica EC3" marka stereo mikroskop altında incelenmiş ve çalışılan her bir takson için herbaryum örneğinin genel görüntüsü ile çiçek durumu, çiçek, meyve ve tohum gibi generatif kısımların detay özellikleri fotoğraflanmıştır. Bunun yanında taksonların teşhisinde büyük öneme sahip çiçeğe ait korolla, korona, stamen ve pistil gibi kısımların ayrıntılı çizimleri yapılmıştır.

\subsection{Yayılış Haritasının Belirlenmesi}

$V$. tmoleum türünün ülkemizdeki yayılış1, ülkemiz sınırları içerisinde yeni tespit edilen, daha önce rapor edilen ve doğrulanmış tüm yayılış, habitat ve popülasyon bilgileri kullanılarak değerlendirilmiştir. Derlenen tüm yayılış bilgileri ArcGIS 9,3 (ESRI, 2011) programı yardımıyla analiz edilerek taksonların yayılış haritaları oluşturulmuştur. Ayrıca hazırlanan bu yayılış haritalarından taksonların ülkemizdeki yaşam alanı (AOO) ve yayılış alanı (EOO) Bs200ProP Görüntü İşleme Sistemi (BS 200 ProP, BAB Görüntüleme Sistemi, Ankara, Türkiye) aracılığı ile hesaplanmıştır.

\section{Bulgular}

\subsection{Morfolojik Özellikler}

3.1.1. Vincetoxicum tmoleum Boissier, Diagn. Pl. Orient. 4: 38.1844 (Şekil 1-3)

Eşadlar: Alexitoxicon raddeanum (Albov) Pobed., Taxon, 11: 174. 1962; Antitoxicum raddeanum (Albov) Pobed., Komarov, Fl. URSS, 18: 695. 1952; A. tmoleum (Boiss.) Pobed., Komarov, Fl. URSS, 18: 694. 1952; Cynanchum tmoleum K. Schum., Engl. et Prantl, Natürl. Pflanzenfam. 4(2): 252. 1895; $C$. raddeanum Kuzn., Fl. Caucasus Crit. 4(1): 442. 1905; Vincetoxicum raddeanum Albov, Prodr. Fl. Colch., Trudy Tiflissk. Bot. Sada 1, Suppl.: 170 (1895); Ic: Fragm. Fl. Geobot. 21: 261, f. 1 a, c. 1975.

Bitki dik, çok y1llık, 40-100 cm (Şekil 1a); gövde kısa kıvrık tüylü (crisped), tüylenme tabandan uca doğru artmakta, dallanmış. Gövdenin alt kısmında bulunan yapraklar 50-95 $\times$ 25-50 mm, ovat, tabanı az çok kamamsı (subcuneate), ucu akut, petiyol 4-10 (-15) mm 
uzunluğunda; üst kısımdaki yapraklar ise 30-75 $\times$ 10-25 mm, ovat-lanseolat, tabanı az çok kamams1 (subcuneate) nadiren yuvarlak (rounded), ucu akuminat, hemen hemen sapsiz (subsessile) ya da petiyol c. $8 \mathrm{~mm}$ uzunlukta; yapraklar kısa kıvrık tüylü (crisped) (Şekil 2a). Çiçek durumu yaprak koltuklarında kimoz, küme (glomerate), 3-25 (-30) çiçekli, belirgin pedunkullu (10-45 mm), pedisel 4-8 $\mathrm{mm}$ uzunluğunda, pedunkul ve pedisel seyrek kısa kıvrık tüylü (crisped) (Şekil 2b); kaliks tabanda birleşik, sepaller 1,4-2,0 × 0,7-0,9 mm, lanseolat, kısa kıvrık tüylü (crisped); korolla yeşilimsi-sarı renkli, çan şeklinde (campanulate), petaller 4,4-4,8 × 2,1-2,7 mm, üçgenimsi, üst yüzeyi yoğun uzun kıvrık yünsü tüylü (lanate) (Şekil 2c, Şekil 3a-b); korona açık sarı renkli, segmentler 1,4-1,6 mm uzunluğunda, tabana kadar ayrılmış, segment uçları üçgenimsi ve dik (Şekil 3c-d). Stamen 0,9-1,2 × 0,7-0,9 mm, anter ucu akuminat (Şekil 3e-f); pistil 1,7-2,2 mm uzunluğunda (Şekil 3g-h). Folikül, 50-75 × 6-10 mm, lanseolat, ucu akut, seyrek veya yoğun kısa kıvrık tüylü (crisped) (Şekil 2d); tohum açık kahverengimsi renkli, 6,3-7,3 × 3,4-4,5 mm, ovoid, kanat $0,2-0,3 \mathrm{~mm}$ genişliğinde; koma $9-$ $15 \mathrm{~mm}$ uzunluğunda, beyaz renkli (Şekil 2e-g).

Çiçeklenme ve Meyve Dönemi: Mayı-Temmuz ve Temmuz-Ağustos

Yetişme Ortamı ve Yükselti: Akan taşlık, kayalık yamaçlar Abies sp., Cedrus sp., Juniperus sp. ve Crataegus sp. açıklıkları, taşlı step alanlar, 600$2900 \mathrm{~m}$

Fitocoğrafik Bölgesi: İran-Turan elementi

\subsubsection{Toplama Bilgileri}

A4 Ankara: Beypazar1, Karagöl'e 10 km kala, taşl1 step alanlar, Crataegus sp., Juniperus sp. açıklıkları, 1570 m, 24.06.2013, S. Güven 60 \& S. Makbul (RUB); Kızılcahamam, Kızılcahamam-Çerkeş arası, Işık Dağı, Güvem çıkış1, akan taşlı yamaçlar, 1097 m, 25.06.2013,
S. Güven $61 \quad \& \quad$ S. Makbul (RUB); Kızılcahamam-Çerkeş yol ayrımı, taşlık, kayalık yamaçlar, $1011 \mathrm{~m}, 25.06 .2013$, S. Güven 65 \& S. Makbul (RUB); A8 Erzurum: Oltu-Olur yolu, Tuzla Köyü yol ayrımı, step alan, 1132 m, 29.06.2013, S. Güven 71 \& S. Makbul (RUB); Oltu-Erzurum yolu, Oltu üstleri, step alan, 1264 $\mathrm{m}, 29.06 .2013$, S. Güven 72 \& S. Makbul (RUB); Olur, Kaledibi Beldesi, taşlı step alanlar, 1054 m, 03.08.2013, S. Güven 87 \& S. Makbul (RUB); A9 Artvin: Artvin-Şavşat yolu, Şavşat'a 40 km kala, Dolishane Kilisesi Hamamı Köyü yol ayrımı, akan kayalık yamaçlar, $666 \mathrm{~m}$, 28.06.2013, S. Güven 67 \& S. Makbul (RUB); Artvin-Şavşat yolu, Çiftehanlar mevkii, akan taşl1 yamaçlar, 600 m, 28.06.2013, S. Güven 68 \& S. Makbul (RUB); Şavşat, Meydancık, taşlı yamaçlar, $1381 \mathrm{~m}, 16.06 .2014$, S. Güven 122 \& S. Makbul (RUB); Şavşat, Meydancık geçidi, taşl1 yamaçlar, 1128 m, 16.06.2014, S. Güven 123 \& S. Makbul (RUB); Şavşat-Meydancık yolu, Dereiçi mevkii, taşlı yamaçlar, $895 \mathrm{~m}$, 24.08.2015, S. Güven 165 \& S. Makbul (RUB); B2 Manisa: Salihli, Salihli-Bozdağ yolu, Bozdağ'a $10 \mathrm{~km}$ kala, Allahdiyen üstleri, akan taşlık, kayalık alanlar, $850 \mathrm{~m}, 20.06 .2013$, S. Güven 48 \& S. Makbul (RUB); B6 Sivas: Mescidli, Yassıcebel-Ağıllar yolunun 1.-2. km'si, akan taşlık yamaçlar, 1297 m, 17.07.2014, S. Güven 145 \& S. Makbul (RUB); B6 Bitlis: Nemrut Dağı, Karater gölü civarı, Populus sp. altlar1, 2335 m, 18.07.2017, S. Güven 176 \& S. Makbul (RUB); C2 Denizli: Sarayköy, Babadağ, Taşoluk Yaylas1, dağ stepi, 1431 m, 20.06.2013, S. Güven 52 \& S. Makbul (RUB); C4 Adana: Aladağ, Maden Ocakları-Acısu yolu üzeri, Pinus sp. orman altlar1, 719 m, 23.05.2014, S. Güven 89 \& S. Makbul (RUB); Mansurlu beldesi, FekeYahyalı yol ayrımı, taşlı step, $1450 \mathrm{~m}$, 25.05.2014, S. Güven 97 \& S. Makbul (RUB); C6 Hatay: Amanos Dağları, açık taşlık alanlar, $1584 \mathrm{~m}, 03.07 .2013$, S. Güven 75 \& S. Makbul (RUB); Amanos Dağları, zirveye yakın taşlık yamaçlar, 1888 m, 03.07.2013, S. Güven 76 \& S. Makbul (RUB). 


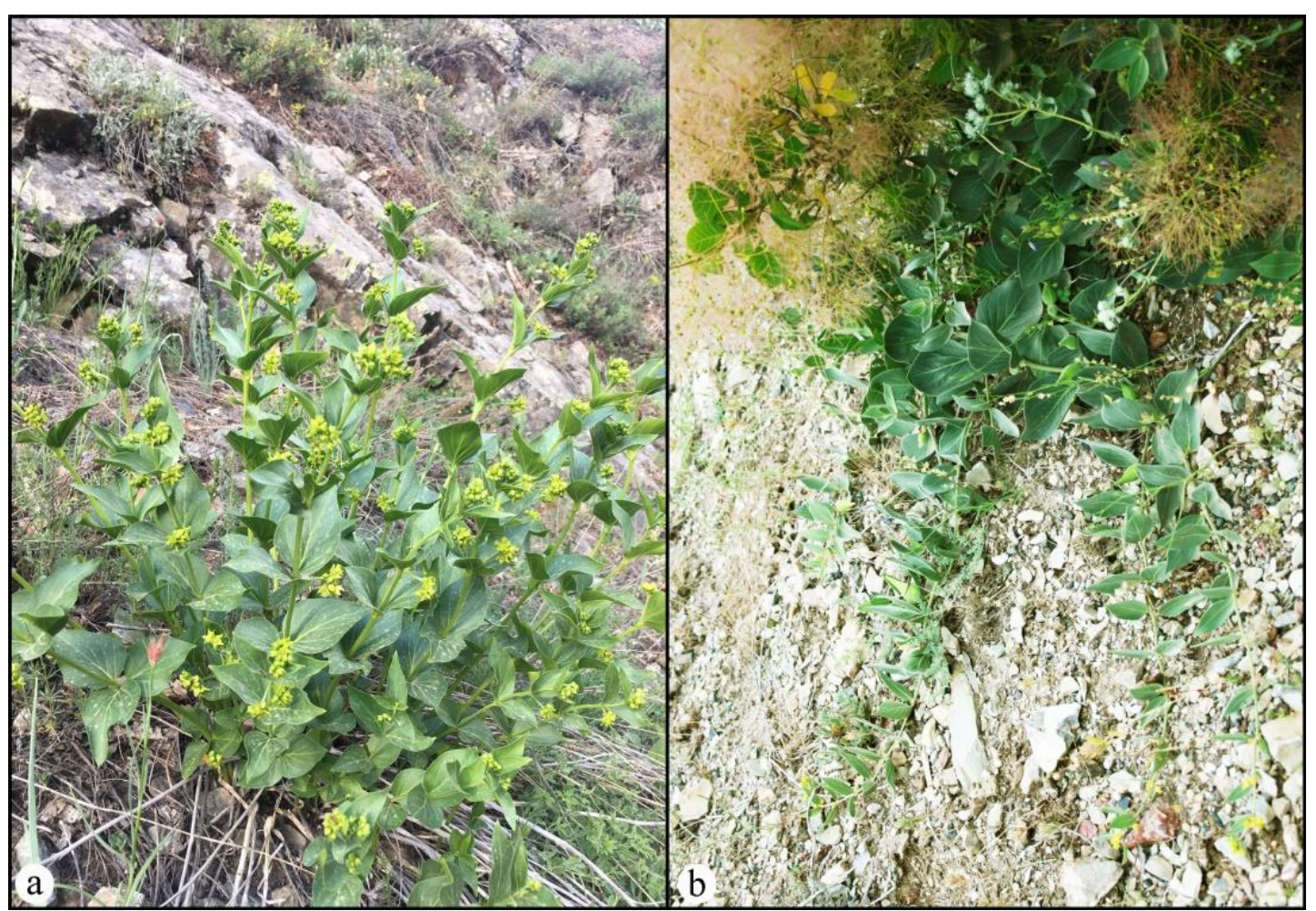

Şekil 1. a. Vincetoxicum tmoleum (Güven 68 \& Makbul), b. Vincetoxicum canescens (Güven 64 \& Makbul, RUB)

Figure 1. a. Vincetoxicum tmoleum (Güven 68 \& Makbul), b. Vincetoxicum canescens (Güven 64 \& Makbul, RUB)

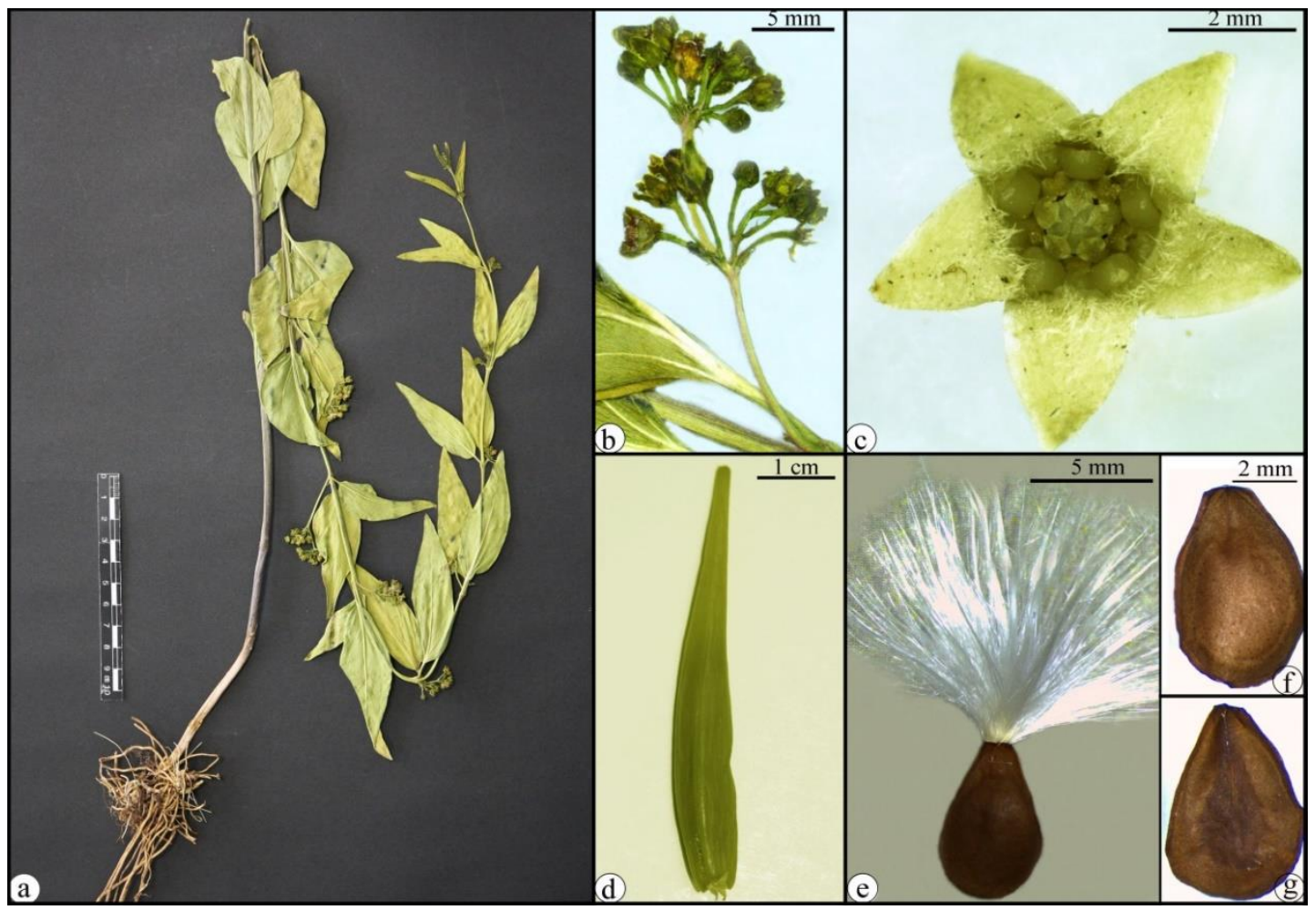

Şekil 2. Vincetoxicum tmoleum (Güven 48 \& Makbul): (a) Herbiye örneği, (b) Çiçek durumu, (c) Çiçek, (d) Meyve, (e) Tohum genel görünüm, (f) Tohum üst yüzey, (g) Tohum alt yüzey.

Figure 2. Vincetoxicum tmoleum (Güven 48 \& Makbul): (a) Habit, (b) Inflorescences, (c) Flower, (d) Fruit, $(e)$ Seed general appearance, $(f)$ Seed dorsal surface, $(g)$ Seed ventral surface. 


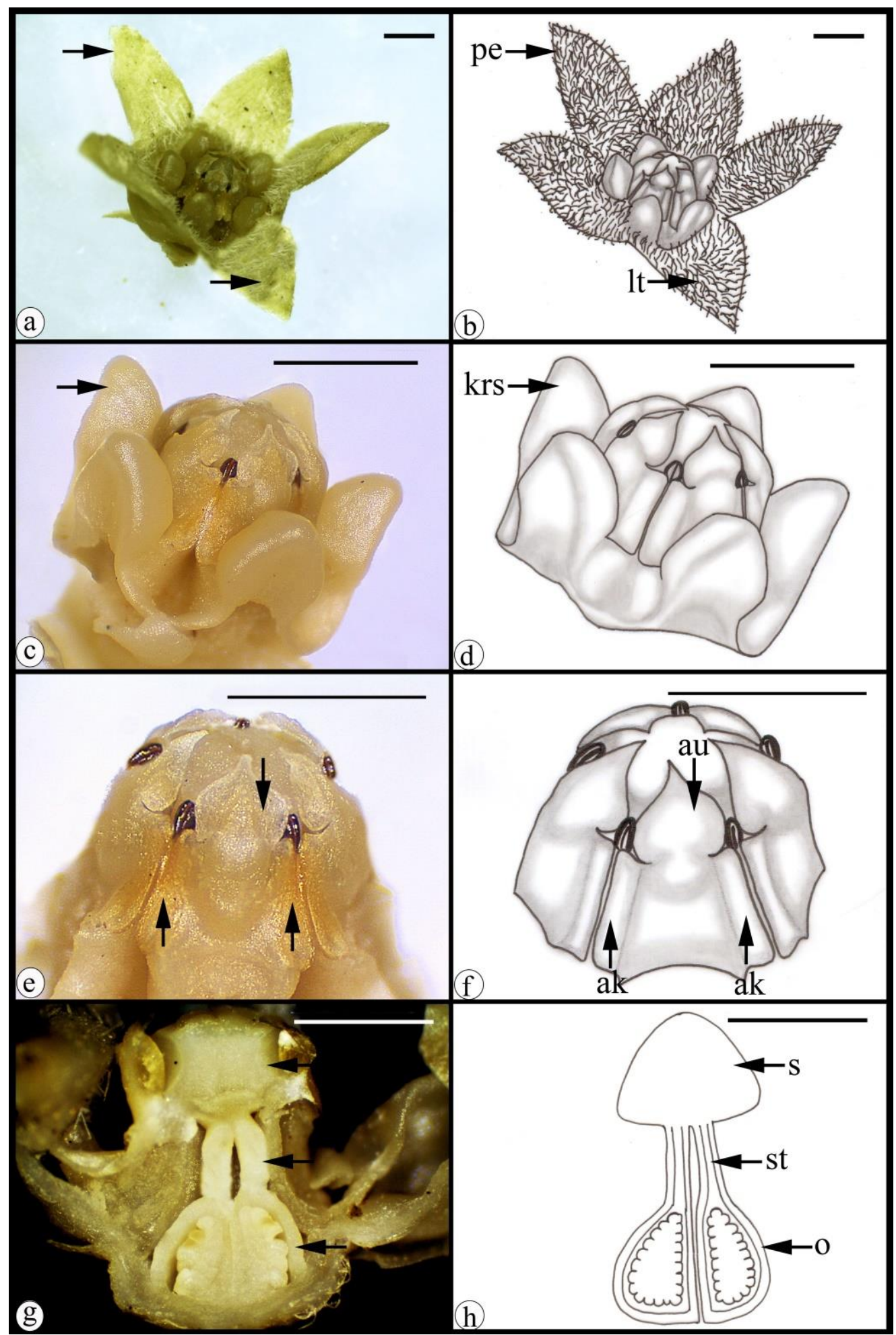

Şekil 3. Vincetoxicum tmoleum (Güven 48 \& Makbul) taksonunun çiçek morfolojisi: (a-b) Korolla genel yapıs1 ve tüylenme durumu, (c-d) Korona, (e-f) Stamen, (g-h) Pistil (a-c-e-g. Işı1k mikroskobu görüntüsü, b-d-f-h. Grafiksel gösterim, ölçek: $1 \mathrm{~mm}$, au: anter ucu, ak: anter kanadı, krs: korona segmenti, lt: lanate, o: ovaryum, pe: petal, s: stigma, st: stilus.

Figure 3. Flower morphology of Vincetoxicum tmoleum (Güven 48 \& Makbul): (a-b) Corolla structure and pubescence, $(c-d)$ Corona, $(e-f)$ Stamen, $(g-h)$ Pistil ( $a-c-e-g$. Light microscope image, $b$ $d-f-h$. Graphical representation, scale: $1 \mathrm{~mm}$, au: anther appendages, ak: anther wing, krs: corona segment, lt: lanate, o: ovary, pe: petal, s: stigma, st: stylus). 


\subsection{Vincetoxicum tmoleum'un Türkiye'deki Yayılışı ve Tehdit Değerlendirmesi}

Türkiye ve Doğu Ege Adaları Florası'nda $V$. tmoleum türü için ülkemizin farklı bölgelerinden toplam 16 lokalite kaydı verilmişti (Browicz, 1978). Bunlara ilave olarak herbaryum çalışmaları ile belirlenen yeni lokalite bilgileri ile 54 yeni lokalite kayd 1 tespit edilmiştir. $\mathrm{Bu}$ çalışma kapsamında da 19 lokaliteden daha örnekleme yapılarak taksonun ülkemizden bilinen lokalite sayısı 89 olarak belirlenmiştir. Derlenen tüm yayılış bilgileri kullanılarak $V$. tmoleum türünün Türkiye'deki yayılış haritası oluşturulmuştur (Şekil 4). Bu yayılış haritası üzerinden türün ülkemizdeki yayılış alanı 517 $979 \mathrm{~km}^{2}$ yaşam alanı ise $115000 \mathrm{~km}^{2}$ olarak hesaplanmıştır. V. tmoleum türünün ülkemizde geniş yayılışa sahip olduğu, populasyonlarının güçlü olduğu ve yakın gelecekte popülasyonları tehdit eden bir risk etmenin olmadığ 1 değerlendirilmiştir.

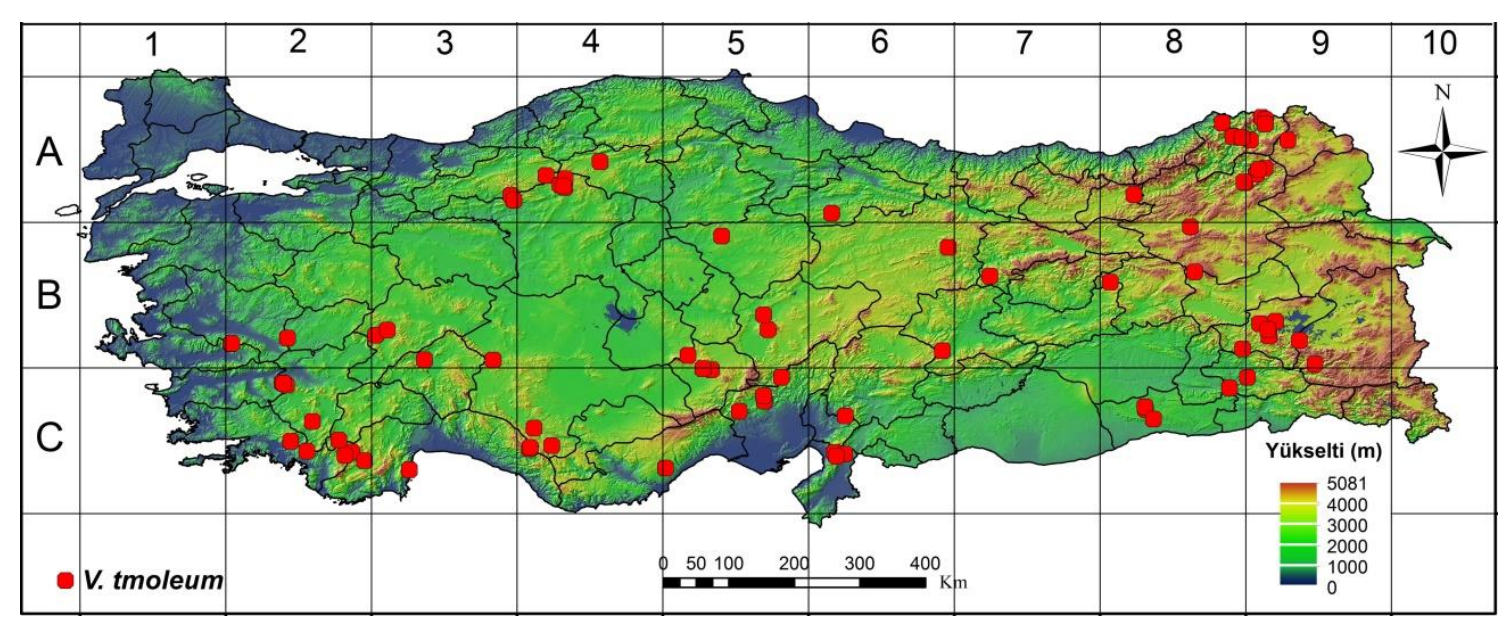

Şekil 4. Vincetoxicum tmoleum taksonunun Türkiye'deki yayılış haritası.

Figure 4. Distribution map of Vincetoxicum tmoleum in Turkey.

\section{Tartışma}

Vincetoxicum cinsi Türkiye'de biri şüpheli kayıt olmak üzere toplam 11 takson ile temsil edilmektedir (Browicz, 1978; Güner, 2012). Morfolojik özellikler ve özellikle de çiçek morfolojisi Vincetoxicum taksonlarının ayrılmasında önemli katkılar sağlamaktadır (Browicz, 1978; Güven, 2017). Korolla rengi ve tüylülük durumu ile korona yapısı birçok ülke florasinda (Pobedimova, 1952; Grossheim, 1967; Rechinger, 1970; Markgraf, 1972; Browicz, 1978; Ali, 1983) cins için anahtar karakterler olarak kullanılmaktadır. Ülkemizde yayılış gösteren Vincetoxicum üyeleri arasinda $V$. hirundinaria beyaz, V. canescens (Şekil 1b) ve $V$. tmoleum (Şekil 2a-b) sarı ila yeşilimsi-sarı, $V$. fuscatum ve $V$. parviflorum kahverengi diğer taksonlar ise koyu morumsu-siyah renkli çiçeklere sahiptir (Güven, 2017). Bunlar içerisinde $V$. canescens ve V. tmoleum (Şekil 3a- b) taksonları çan şeklinde (campanulate) korolla ve üçgenimsi petaller ile karakterize olurken diğer taksonlar disk şeklinde (rotate) korolla ve oblong veya ovat-oblong petallere sahiptir (Güven, 2017).

Ülkemiz Vincetoxicum taksonları arasında sarımsı çiçekleri ile karakterize olan $V$. canescens ve $V$. tmoleum taksonları çiçek morfolojisi yönünden de oldukça benzer özellikler sergilemektedirler. Her iki türün mensupları sarımsı çan şeklinde (campanulate) korollaya ve üçgenimsi yoğun tüylü petallere, segmentleri tabana kadar ayrılmış koronaya ve akuminat anter ucuna sahiptir. Bu iki tür ayrıca ovoid polinyumlara sahip olması ile de benzerlikler göstermektedir (Güven vd., 2015, Güven, 2017). Ancak bu iki takson genel morfolojik özellikleri yönünden kolayca birbirinden ayrilabilmektedir. $V$. canescens taksonları yatık (decumbent) ve gri karışık sık 
tüylü (canescent-tomentose) gövde ve ovoid meyve şekli ile karakterize olurken (Şekil 1b) $V$. tmoleum türü ise dik ve yüzeyi kısa kıvrık tüylü (crisped) gövdeye (Şekil 1) ve lanseolat meyvelere (Şekil 2d) sahiptir. Benzer şekilde corolla tüylenmesi de bu iki takson arasında farkl11ık oluşturmaktadır. Korolla üst yüzeyi $V$. canescens taksonlarıda yoğun beyaz yumuşak tüylü (hirsute) iken $V$. tmoleum türünde yoğun uzun kıvrık yünsü tüyler (lanate) (Şekil3a-b) ile kaplıdır (Tablo 1).

Tablo 1. Vincetoxicum tmoleum ve Vincetoxicum canescens türlerinin morfolojik özellikleri yönünden karşılaştırılması.

Table 1. Comparison of Vincetoxicum tmoleum and Vincetoxicum canescens species in terms of morphological features.

\begin{tabular}{|c|c|c|c|}
\hline Bitki kısmı & & V.tmoleum & V. canescens \\
\hline \multirow[t]{3}{*}{ Gövde } & Boyu $(\mathrm{cm})$ & $40-100$ & $25-80$ \\
\hline & Tüy tipi & k1sa kıvrık tüylü (crisped) & $\begin{array}{l}\text { gri karışı sık tüylü } \\
\text { (canescent-tomentose) }\end{array}$ \\
\hline & Tipi & dik & yatık (decumbent) \\
\hline \multirow{4}{*}{$\begin{array}{l}\text { Gövde alt } \\
\text { yapraklar }\end{array}$} & Şekli & ovat & ovat \\
\hline & Ucu & akut & akut \\
\hline & Tabanı & az çok kamamsı (subcuneate) & yuvarlak \\
\hline & Tüy tipi & k1sa kıvrık tüylü & gri karışık sık tüylü \\
\hline \multirow{4}{*}{$\begin{array}{l}\text { Gövde üst } \\
\text { yapraklar }\end{array}$} & Şekli & ovat-lanseolat & ovat-lanseolat \\
\hline & Ucu & akuminat & akuminat \\
\hline & Tabanı & az çok kamamsı nadiren yuvarlak & yuvarlak \\
\hline & Tüy tipi & k1sa k1vrık tüylü & gri karışık sık tüylü \\
\hline \multirow[t]{15}{*}{ Çiçek } & Pedunkul uzunluğu (mm) & $10-45$ & sapsiz ya da $10-30 \mathrm{~mm}$ \\
\hline & Pedunkul tüy tipi & k1sa kıvrık tüylü & gri karışık sık tüylü \\
\hline & $\begin{array}{l}\text { Çiçek durumundaki çiçek } \\
\text { sayısı }\end{array}$ & $3-30$ & $5-25$ \\
\hline & Pedisel boyu (mm) & $4-8$ & subsessil ya da 5 \\
\hline & Pedisel tüy tipi & kısa kıvrık tüylü & gri karışık sık tüylü \\
\hline & Kaliks & tabanda birleşik & tabanda birleşik \\
\hline & Sepal şekli & lanseolat & lanseolat \\
\hline & Sepal tüy tipi & k1sa k1vrık tüylü & gri karışık sık tüylü \\
\hline & Korolla şekli & çan şeklinde (campanulate) & çan şeklinde (campanulate) \\
\hline & Korolla rengi & yeşilimsi-sarı & sar1 \\
\hline & $\begin{array}{l}\text { Korolla üst yüzey tüylenmesi } \\
\text { ve tüy tipi }\end{array}$ & $\begin{array}{l}\text { yoğun uzun kıvrık yünsü tüylü } \\
\text { (lanate) }\end{array}$ & $\begin{array}{l}\text { yoğun beyaz yumuşak } \\
\text { tüylü (hirsute) }\end{array}$ \\
\hline & Korona segment durumu & ayr1 & ayr1 \\
\hline & Korona segment ucu & üçgenimsi ve dik & üçgenimsi ve dik \\
\hline & Korona rengi & açık sarı & açık sarı \\
\hline & Anter ucu & akuminat & akuminat \\
\hline \multirow[t]{4}{*}{ Folikül } & Folikül şekli & lanseolat & ovoid \\
\hline & Eni (mm) & $6-10$ & $15-20$ \\
\hline & Boyu (mm) & $50-75$ & $45-65$ \\
\hline & $\begin{array}{l}\text { Folikül tüylenmesi ve tüy } \\
\text { tipi }\end{array}$ & $\begin{array}{l}\text { seyrek ya da yoğun kısa kıvrık } \\
\text { tüylü }\end{array}$ & yoğun kısa kıvrık tüylü \\
\hline \multirow[t]{5}{*}{ Tohum } & Şekli & ovoit & ovoit \\
\hline & Eni (mm) & $3,4-4,5$ & $4.0-5,4$ \\
\hline & Boyu (mm) & $6,3-7,3$ & $7,0-8,1$ \\
\hline & Kanat genişliği (mm) & $0,2-0,3$ & $0,2-0,5$ \\
\hline & Koma uzunluğu (mm) & $9-15$ & $15-24$ \\
\hline
\end{tabular}

Browicz (1978), Türkiye ve Doğu Ege Adaları Florası'nda $V$. raddeanum ve $V$. tmoleum'un morfolojik olarak birbirlerine çok benzer iki takson olduğunu, sadece meyvenin tüylülük özelliği ile ayrıldığını rapor etmiştir. Araştırıcı 
bu nedenle $V$. raddeanum türünü ülkemiz için şüpheli kayıt olarak vermiştir. Daha sonra Greuter vd. (1984) V. raddeanum türünün morfolojik olarak $V$. tmoleum ile benzer özellikler taşıdığını ve bu yüzden de sinonim olması gerektiğini rapor etmişlerdir. Albov (1895) V. raddeanum'u tanımlarken bu türün $V$. tmoleum ile yakın morfolojik özellikler gösterdiğini ancak daha küçük çiçek ve yapraklara sahip olması yönüyle $V$. tmoleum'dan ayrıldığını belirtmiştir. Araştırıcı bu iki taksonun daha detaylı bir şekilde ele alınmasını önermiştir. $\mathrm{Bu}$ çalışma ile, $V$. raddeanum olarak teşhis edilmiş TBI (Woronow 1904 (1086-1089)!, Woronow 1911 (4675)!, Woronow 1911 (5836)!, Sosnovsky 1911!, 1912!, König 1903!, 1912!, Sapozkihov 1916!) ve LE (Turkevicz 1914 (762)!, Nesterov 1910!)'de bulunan ülkemize ait bazı örneklere ulaşıımıştır. Ayrıca bu çalışma ile söz konusu taksonun muhtemel yayılış alanlarında detaylı arazi çalışmaları yapılmış ve çok sayıda örnek (Güven 67, Güven 68, Güven 71, Güven 72, Güven 87, Güven 122, Güven 123, Güven 165) toplanmıştır. Elde edilen bulgular $V$. raddeanum'un tip örneğinin morfolojik betimi ile karşılaştırılmıştır. İncelenen örnekler değerlendirildiğinde gerek $V$. raddeanum olarak adlandırılan örnekler gerekse ülkemizden toplanan $V$. tmoleum örneklerinin meyve yüzeyinde farklı tüy yoğunluklarının olduğu görülmüştür. Benzer şekilde $V$. tmoleum örnekleri içerisinde de farklı tüy yoğunluğuna ait meyvelerin olduğu görülmüştür. $\mathrm{Bu}$ durum meyve yüzeyindeki tüylenmenin sadece bir tür içi varyasyon olduğu görüşünü desteklemektedir. Ayrıca bu örneklere ait anatomik, palinolojik, sitolojik ve moleküler verilerin de morfolojik verileri desteklediği görülmektedir (Güven 2017). Bu durum Greuter vd. (1984) tarafindan öne sürülen $V$. raddeanum türünün $V$. tmoleum taksonunun sinonimi olduğu fikrini destekler niteliktedir.

V. tmoleum ülkemizde geniş yayılışa sahip olan taksonlardan birisidir (Browicz, 1978; Güner, 2012). Browich (1978) taksonun Anadolu'da 16 farklı lokalitede yayılış gösterdiğini rapor etmiştir. Herbaryum incelemeleri kapsamında türe ait 54 farklı lokaliteden toplanan örneklere ulaşılarak yayılış bilgileri derlenmiştir. Ayrıca arazi çalışmaları ile ülkemizden 19 lokaliteden daha ilk kez örnekleme yapılmış ve derlenen yayılış bilgileri neticesinde taksonun ülkemizde doğrulanmış 89 lokaliteden yayılış gösterdiği tespit edilmiştir. Elde edilen bulgular türün Kuzey Doğu Anadolu, İç ve Doğu Anadolu Bölgesi ile Anadolu'nun güney bölgelerinde yayılış gösterdiğini ortaya koymaktadır. $V$. tmoleum ulusal ölçekteki tehlike kategorisi IUCN (2017)'ye göre değerlendirildiğinde oldukça geniş bir yayıllışa sahip olduğu ve bu nedenle de herhangi bir risk grubuna dahil edilmesine gerek olmadığı görülmüştür. Yine popülasyonların birey sayısı ve tohum verimliliği yönünden oldukça güçlü olması ve alanı iyi kullanması yakın gelecekte herhangi bir risk grubunda değerlendirilmesine gerek olmadığını desteklemektedir.

$\mathrm{Bu}$ çalşma ile Vincetoxicum tmoleum türünün morfolojik betimi ayrıntılı karakterler eklenerek genişletilmiş, arazi çalışmaları ile ülkemiz sınırları içerisinde yeni tespit edilen ve daha önce rapor edilen tüm yayıllış, habitat ve popülasyon bilgileri güncellenmiş, bu yayıllış bilgileri ve arazi gözlemleri ile tehdit faktörleri ve değerlendirilmesi yeniden yapılarak tür için önemli taksonomik katkılar sağlanmıştır.

\section{Teşekkür}

$\mathrm{Bu}$ çalışma finanasal olarak RTEÜ-BAP (Proje No: 2013.102.03.1) tarafından desteklenmiştir.

\section{Kaynaklar}

Albov, N. (1895). Prodromus Florae Colchicae. Tiflis, Zheneva, $290 \mathrm{~s}$.

Ali, S.I. (1983). Flora of Pakistan, No. 150. University of Karachi, 65 s., Nasir, E. and Ali, S.I. (Ed.), 1-65.

Altundağ, E., Öztürk, M. (2011). Ethnomedicinal studies on the plant resources of east Anatolia, Turkey. Procedia Social and Behavioral Sciences, 19, 756-777. DOI: 10.1016/j.sbspro.2011.05.195. 
Baytop, T. (1984). Türkiye'de Bitkiler ile Tedavi. İstanbul Üniversitesi Yayınları, No: 3255, $520 \mathrm{~s}$.

Boissier E.P. (1875). Vincetoxicum Maench. In: Boissier E.P. (ed.) Flora Orientalis: 51-56. H. Georg, Basileae, Genevae.Browicz, K. (1978). Flora of Turkey and the East Aegean Islands, Vol. 6. Edinburgh University Press, 825 s., Davis, P.H. (Ed.), 167-173.

DiTommaso, A., Lawlor, F.M., Darbyshire, S.J. (2005). The biology of invasive alien plants in Canada, 2, Cynanchum rossicum (Kleopow) Borhidi [=Vincetoxicum rossicum (Kleopow) Barbar.] and Cynanchum louiseae (L.) Kartesz \& Gandhi [= Vincetoxicum nigrum (L.) Moench]. Canadian Journal of Plant Science, 85, 243-263.

Doğan, A. (2008). Ovacık (Tuceli) Yöresinin geleneksel halk ilacı olarak kullanılan bitkileri. Yüksek Lisans Tezi. Marmara Üniversitesi, Sağlık Bilimleri Enstitüsü, İstanbul, Türkiye, 111 s., 16.

Douglass, C.H., Weston, L.A., DiTommaso, A. (2009). Management of Invasive Weeds, Vol. 5, Invading Nature-Springer Series in Invasion Ecology. Springer, Netherlands, $1^{\text {st }}$ Edition, ISBN: 978-90-481-8089-9, 364 s., Inderjit (Ed.), 261277.

ESRI, (2011). ArcGIS Desktop: Release 10. Redlands, CA: Environmental Systems Research Institute.

Greuter, W., Burdet, H.M., Long, G. (1984). MedChecklist 1: A Critical Inventory of Vascular Plants of the Circum-Mediterranean Countries. Optima, $1^{\text {st }}$ Edition, ISBN: 9782827701513, 330 s.

Grossheim, A.A. (1967). Flora of the Caucasus, Vol. 7. Academy of Science of the USSR, 893 s., Grossheim, A.A. (Ed.), 221-225.

Güner, A. (2012). Vincetoxicum Wolf. In: Güner A., Aslan S., Ekim T., Vural M., Babaç M.T. (eds) Türkiye bitkileri listesi (Damarlı bitkiler): 85-86. Nezahat Gökyiğit Botanik Bahçesi ve Flora Araştırmaları Derneği Yayını.

Güven, S. (2017). Türkiye Vincetoxicum (Apocynaceae Asclepiadoideae) cinsinin taksonomik revizyonu. Doktora Tezi, Recep Tayyip Erdoğan Üniversitesi, Fen Bilimleri Enstitüsü, Rize, Türkiye.

Güven S., Makbul S., Coskuncelebi K., Pınar N.M. (2015). Pollinarium morphology of the genus Vincetoxicum Wolf (Apocynaceae:
Asclepiadoideae) in Turkey. Phytotaxa, 230 (1): 22-38. https://doi.org/10.11646/phytotaxa.230.1.2

Güven S., Makbul S., Coşkunçelebi K. (2019). Contribution to chromosome numbers and phylogeny of Turkish Vincetoxicum Wolf (Apocynaceae, Asclepiadoideae). European Journal of Taxonomy, 590: 1-19. https://doi.org/10.5852/ejt.2019.590

IUCN. (2017). The IUCN Red List of Threatened Species. Version 2017-3. http://www.iucnredlist.org.

Lavault, M., Richomme, P., Bruneton, J. (1999). Acetophenones and new pregnane glycosides from the roots of Vincetoxicum hirundinaria. Fitoterapia, 70, 216-220.

Liede, S. (1996). Cynanchum - Rhodostegiella Vincetoxicum - Tylophora (Asclepiadaceae): new considerations on an old problem. Taxon, 45, 193211.

Liede-Schumann, S., Khanum, R., Mumtaz, A.S., Gherghel, I., Pahlevani, A. (2016). Going West- a subtropical lineage (Vincetoxicum, Apocynaceae: Asclepiadoideae) expanding into Europe. Molecular Phylogenetics and Evolution, 94, 436446.

Markgraf, F. (1972). Flora Europaea, Vol. 3. Cambridge University Press, ISBN: 9780521084895, 399 s., Tutin, T.G. vd., (Ed.), 71-73.

Nowak, R., Kisiel, W. (2000). Hancokinol from Vincetoxicum officinale. Fitoterapia, 71, 584-586.

Pobedimova, G. (1952). Flora of the USSR, Vol. 18. Academy of Science of the USSR Press, 600 s., Shishkin, B.K. and Bobrov, E.G. (Ed.), 496-521.

Rechinger, K.H. (1970). Flora Iranica, Vol. 73: 10. Akademische Druck und Verlagsanstalt, $21 \mathrm{~s}$.

Sheeley, S.E., Raynal, D.J. (1996). The distribution and status of species of Vincetoxicum in eastern North America. Bulletin of the Torrey Botanical Club, 123(2), 148-156. DOI: 10.2307/2996072.

Tuzlac1, E. (2011). Türkiye Bitkileri Sözlüğü (Ciltli) Türkçe-Latince, Latince-Türkçe Bitki Adlarının Özel Açılklamaları. Alfa Basım Yayım Dağıtım, 2. Bask1, ISBN: 6051063614, 1294 s. 
Ek 1. Vincetoxicum tmoleum'un Türkiye'deki Diğer Yayılış Bilgileri

A3 Ankara: Beypazarı, Karagöl mevkii, 1500 m, 08.09.1971, Y. Akman 8446, ANK!; A4 Ankara: Kızılcahamam, Akdere, 16.08.1960, 1100-1400 m, Khan vd. 698, ANK!, E (00646468!); Kizılcahamam-Gerede aras1, Kızılcahamam yakını, 27.08.1975, Baytop 33646, ISTE!; Yabanabat, 12.07.1933, W. Kotte, ANK!; A4 Çankırı: Atkaracalar, Dumanlı Dağı, Bozkuş Yaylası, taşlı step alanlar, $1250 \mathrm{~m}$, 10.07.1992, A. Duman 1655, GAZİ; A6 Tokat: Artova, Çermik-Çöte arası, Çöteye $1 \mathrm{~km}$ kala, 1200 m, 06.06.1950, R. İlarslan 1083, ANK!; A8 Gümüşhane: Gümüşhane-Bayburt yolu, Kan Köprü civarı (Köprü Chan), 1220 m, 30.07.1859, Kotschy 284, B!; A8 Artvin: Borçka vadisi, 30.05.1904, G. Woronow 1086, TBI!; Ardanuç çevresi, kayalık yamaçlar, 18.05.1904, G. Woronow 1087, TBI!; nr. Artvin, 20.05.1904, G. Woronow 1088, TBI!; 13.05.1904, G. Woronow 1089, TBI!; 26.07.1911, G. Woronow 4675, TBI!; 26.07.1911, G. Woronow 5836, TBI!; 09.06.1914, S. Turkevicz 762, LE!; A8 Erzurum: Oltu çevresi, 18.06.1911, Sosnovsky, TBI!, 26.06.1911; Sosnovsky, TBI!; 20.05.1912, Sosnovsky, TBI!; 06.07.1912, König, TBI!; Oltu Çayı çevresi, 15.07.1903, König, TBI!; 16.07.1910, Nesterov, LE!; Erzurum, Sonömer $\mathrm{Su}$, kuru taşlı yamaçlar, 29.06.1916, V. Sapozkihov, TBI!; Tortum-Oltu aras1, Tuzla Köyü civarı, 28.05.1971, Baytop 19921, ISTE!, E (00646470!); A9 Erzurum: Şenkaya, Pertivan Köyü’nden Balkaya Köyü'ne giden yol boyunca, korunmuş alanlar (Balkaya Köyü çevresi), 1750 m, 11.08.1981, Demirkuş 2356, HUB (19101!); Olur, 11.08.1968, T. Baytop 14335, ISTE!, E (00646469!); B2 İzmir: Ödemiş, Bozdağ (mt. Tmolo), 06.1842, P.E. Boissier, JE (00000010!), GOET (005778!), K (000894596!), P (02428143!); 01.07.1854, B. Balansa 291, B!; 07.06.1946, A. Heil \& M. Baş, ISTF (6546!); 07.07.1962, C. Regel 39, E (00646482!); 11.07.1965, C. Regel, EGE (12578!), E (00646483!); 03.07.1966, C. Regel \& M. Aydar, EGE (12580!), E (00646481!); 18.07.1997, P. Hein 4252, B!, Battler \& Erben 17468; Ödemiş,
Gölcük, 08.06.1946, A. Heil \& M. Baş, ISTF (6628!); Ödemiş, Bozdağ, Büyükçavdar Yaylası sirtlar1, 1400 m, 09.10.1980, Baytop 45903, ISTE!; B3 Afyon: Sandıklı Deresi kıyıları, 14.07.1954, K. Karamanoğlu 5022, ANK!; Afyon-Sandiklı karayolunun 25. km'si, 1100 m, 03.08.1993, Z. Aytaç 6486 vd., GAZİ!, Sandıklı, Sorkun'un kuzey yamaçları, 1100 m, 23.07.1983, Y. Gemici 2526, EGE (25888!); B3 Konya: Akşehir, Sultan Dağı, Doğanhisar, Kemer Köy, 1300 m, 25.06.1985, Akman 13722, ANK!; B3 Isparta: Senirkent, Garip Köyü çıkışı, Cedrus sp. ormanı üzerindeki ağaçsız kuşak,1900-2050 m, 20.07.1983, L. Bekat 1200 vd., EGE (35615!); B5 Yozgat: Yozgat civar1, 12.09.1971, B!; B5 Kayseri: Erciyes Dağı (Cappadocia, Argaei), 1500-1600 m, 18.05.1890, Bornmüller 1625, B!, E (00646475!); Merdivenli, 20.07.1944, Bağda 22, ANK!; B5 Niğde: Ortakayaardı vadisi, step, $1200 \mathrm{~m}, 19.06 .1952$, P.H. Davis 19049, ANK!, ISTE, ISTO (2271!), E (00646486!); Fesleğen Köyü üstleri, 1600 m, 17.06.1977, Baytop 37516, ISTE!; Kitreli Kasbas1, 1500 m, 23.06.1995, F. Ertuğ 523, GAZI!; B6 Malatya: Dedeyazı Köyü, Koru Yaylas1, dağ stepi, $1500 \mathrm{~m}, 17.08 .1966$, Peşmen 1075, EGE (5370!); B7 Erzincan: Egin (Kemaliye), P. Sintenis 1890:2523; B8 Muş: Bingöl Dağı'nın güneybatı yamaçları, taşlık alanlar, 2000 m, 10.07.1966, P.H. Davis 46193, ISTO (10138!), E (00646466!); B8 Bingöl: Günlük Köyü, orman altları ve yamaçlar, 1200 m, 12.06.1991, H. Aktaş, ISTO (29679!); B9 Van: Çatak, Kavuşşahap Dağları, 2150 m, kayalık alanlar, 24.07.1954, P.H. Davis 23080 \& O.V. Polunin, E (00646464!); 39 Bitlis: Karadağ, Kotum civarı, 2000 m, 23.08.1954, P.H. 24557, ANK!, E (00646472!); Bitlis civar1, dağ stepi, 12.06.1956, Huber-Morath 59, ANK!; Ahlat-Tatvan aras1, 04.06.1971, Baytop 20011, ISTE!, E (00646471!); Tatvan, Pelli Köyü üstleri, metamorfik yamaçlar, $1750 \mathrm{~m}$, 14.05.1972, Peşmen 3114, HUB (19097!); Tatvan, Nemrut Dağı, batı yamaçları, volkanik kayal1klar, 1900-2900 m, 18.06.1972, Peşmen 2895, HUB!; Tatvan, Sorgun, Van Gölü üstleri, volkanik yamaçlar, $1700 \mathrm{~m}, 25.07 .1972, \mathrm{H}$. Peşmen 3113, HUB (19096!); Bitlis-Baykan 
karayolunun 30. km'si, kayalık yamaçlar, 1040 m,19.06.1976, H. Dem, Ö. Saya \& G. Kay, ISTF (29647!); C2 Muğla: Fethiye, Kara Tepe, Seki Yaylası (Lehi Yayla) civarı, 1370 m, 03.08.1947, P.H. Davis 13887, ISTO (2421!), E (00646462!); Fethiye'nin 35 km kuzeyi, Çal Dağ1 yamaçları, Cedrus libani ormanı açıklıkları, taşlık kayalık alanlar, 1900 m, 09.08.1968, M.K.R. Lambert \& T.K. Thorp 558, E (00646474!); Köyceğiz, Sandras Dağı, Sazak-Çövenli yolu, Çövenli’ye 2 km kala, taşlı yamaçlar, orman altı, $1300 \mathrm{~m}$, 24.08.1977, N. Özhatay 1421, ISTO (19602!); Dirmil, Kuzu Kulağı Yaylası, $1450 \mathrm{~m}$, 06.06.1988, F. Speta, W (2016-0008494!); Gülübeli Geçidi, 1600 m, 07.06.1988, F. Speta, W (2016-0008495!); C2 Denizli: Bozdağ, Geyran Yaylas1, 1500 m, 13.08.1969, Walther, EGE (2672!); Sarayköy, Babadağ, $1700 \mathrm{~m}$, 23.08.1950, P.H. Davis 18434, E (00646485!); Sarayköy, Babadağ, Türtü Kayası, Kasap tarlası, 1400 m, 16.07.1983, Ş. Yıldırımlı 5549, HUB (19099!); Sarayköy, Babadağ, Gökbel Yaylası, yüksek dağ stepi, $1710 \mathrm{~m}, 04.07 .1996$, S. Oluk 1601, EGE (34534!); Sarayköy, Babadağ, Karacasu, Taşdelen mevkii, Aktaş Tepe yamaçları, açık kayalık alanlar, $1900 \mathrm{~m}$, 25.06.2000, Ö. Eren \& G. Parolly 7590, B!; C2 Antalya: Elmalı, Koçeve, 05.08.1964, F. Demirdöğen, ISTO (9700!); C3 Antalya: Tahtalı Dağı, Kemer civarı, açık taşlı yamaçlar, 16002300 m, 01.05.2000, Ö. Eren \& G. Parolly 5274, B!; C4 Konya: Kazancı Deresi, Geyik Dağ, Bozkır, 1830 m, 01.09.1947, P. H. Davis 14605, ANK!, E (00646487!); Taşkent, dere boyunca, Kulakbendi-Ditren-Aktaş-Kireç ocağı-Eşenin
Suyu-Su Gözü-Ekşielma Yaylası mevkileri, Abies sp., Cedrus sp. orman açıklıkları, 15001750 m, 22.07.1985, Ş. Y1ldırımlı 8471, HUB (19098!), EGE (32195!); C4 Antalya: Geyik Dağları, 07.1845, T.H.H. Heldreich, E (00646489!); Orta Toroslar, Geyik Dağları, Akdağ K 3654 - D 32 10, taşlı step yamaçlar, 2100 m, 21.06.1992, P. Hein A 67-6, B!; C5 Mersin: Kızılgeçit, 980 m, 22.06.1971, T. Uslu 80, ANK!; C5 Adana: Seyhan, Karaisal1, Pos orman1, Tüylü Tepe, $2000 \mathrm{~m}, 05.06 .1952$, İ. Aktaş, ISTO (1020!), E (00646477!); C6 Adana: Aladağ, 1600 m, 29.18.1938, Ellenberg 420, B!; C6 Osmaniye: Düziçi, Düldül Dağ1, Atlık Yaylas1, 1700-1800 m, 26.08.1944, P. H. Davis 16364, ANK!, ISTE!, E (00646463!); C6 Hatay: Amanos Dağları, 1500-2100 m, 07.1908, M. Haradjian 2353, E (00646478!); Amanos Dağları, 900-2100 m, 08.1913, M. Haradjian 4583, E (00646480!); Amanos Dağları, DörtyolDaz Dağı arası, Topaktaş Yaylası, Harmankaya Tepesi, açık kayalık alanlar, 1830-2170 m, 06.10.1988, H. Kehl 88, B!; C8 Mardin: nr Khurs, 13.06.1888, P. Sintenis 1008, E (00646473!); Mardin-Diyarbakır arası, Sultanköy çevresi, kalkerli alanlar, 1050-1150 m, 16.06.1985, A. Güner 6472 \& E. Gündüz, HUB (19100!); Sultanköy-Gürpınar yolunun 2. km'si, taşlık yamaçlar ve kayalıklar, 945 m, 04.07.1976, H. Dem \& G. Kay, ISTF (29703!); C8 Siirt: Eruh yolu, kayalık step, 630 m, 09.06.2009, S. Aslan 3799 vd., GAZİ!; Botan Çayı'nın girişi, kayalık alan, 650-700 m, 19.05.2009, K 3788 46 - D 4188 80, S. Aslan 3609 vd., GAZİ!. 